\title{
Synthesis of new artificial receptors for anion recognition: calix[4]arenes thiourea derivative
}

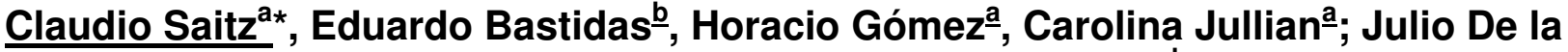 \\ Fuente ${ }^{\mathrm{a}}$, Hernán Pessoa ${ }^{\mathrm{a}}$, Carlos Escobar ${ }^{\mathrm{b}}$
}

\begin{abstract}
a:Departamento de Química Orgánica y Físico-Química, Facultad de Cs. Químicas y Farmaceúticas, Sergio Livingstone 1007, Casilla 233, Santiago 1, Universidad de Chile, b: Departamento de Cs. Químicas, Facultad de Ecología y Recursos Naturales, Universidad Andrés Bello, Av. República 275, Santiago, Chile ${ }^{*}$-mail corresponding author:clsaitz@ciq.uchile.cl
\end{abstract}

Keywords: calix[4]arene, thiourea derivative, anion recognition

\section{INTRODUCTION}

Calixarenes are macrocyclic compounds composed by phenolic units, connected by methylene bridges, to form a hydrophobic cavity capable of generating inclusion complexes with a variety of molecules ${ }^{\text {. }}$. Calixarenes are particularly attractive scaffolds for receptor development, through the incorporation of numerous ligands for co-operative binding of anions. Since their discovery calixarenes have been widely used in the last two decades as building blocks for the synthesis of receptors for cations and neutral molecules. The development of synthetic anion receptors has been slow in comparison to cation receptors. Anions play a number of fundamental roles in biological and chemical processes and the development of selective synthetic anion receptors is an area of current importance.

Calixarenes bearing urea and thiourea moieties have also been prepared offering the advantages of increased proton acidity and additional proton interactions with the same directionality which can act co-operatively in binding an anion.

On the basis of the precedent information, we have synthesized and characterized new functionalized calixarenes with thiourea in the lower rim. Also, some known molecules were incorporated as fluorophores, and their binding properties with various anions, including fluoride, chloride, acetate, among others are being investigated by fluorescent titrations, Job plot experiments and ${ }^{1} \mathrm{H}$ NMR spectroscopy.

\section{RESULTS AND DISCUSSION}

The synthetic strategy to modify lower rim has been successfully developed before in two steps; in the first stage pattern calixarene 1 was alkylated with bromoacetonitrile followed by reduction by $\mathrm{LiAlH}_{4}{ }^{2}$ yielding di-amine calixarene 2. We have previously performed the transformation of $\mathbf{1}$ into the corresponding diso thiocyanate derivative $\mathbf{3}$ in excellent yields, using thiophosgene ${ }^{3}$ (Scheme 1). Recently, calixarene derivative di-amine $\mathbf{2}$ and diisothiocyanate 3 reacted with amines or isothiocyanates to give calixarenes derivative Cth1 with thiourea bridges. The following amines, and isothiocyanates were used, some are commercially available and others have been prepared in this laboratory: 2-amino-anthracene, 2-anthraceneNCS, PhNCS, 2-amino- and 6-aminobenzothiazole.

\section{CONCLUSION}

Calix[4]arenes 4-8 containing thiourea group were synthesized and the binding properties for anions were investigated using tetrabutylammonium salts.

\section{ACKNOWLEDGEMENTS}

We thank FONDECYT (Grant 1100906) and VID Universidad de Chile (Grant ENL-09/03)

\section{REFERENCES}

${ }^{1}$ Gutsche C. David, "Calixarenes Revisited"(Ed. Stoddart J.F.), Royal Society of Chemistry, Cambridge, England, 1998.

${ }^{2}$ W. C. Zhang, Z. T. Huang, Synthesis, 1997, 1907

${ }^{3}$ F. Santoyo-Gonzalez, A. Torres-Pinedo, C. Saitz-Barría, Eur. J. Org. Chem., 2000, 3587

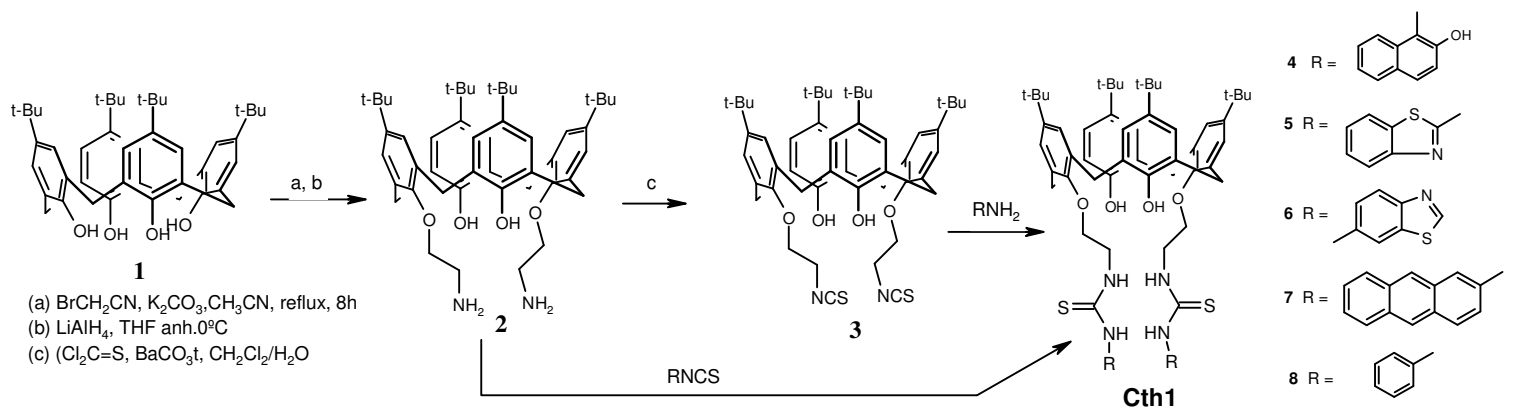

$14^{\text {th }}$ Brazilian Meeting on Organic Synthesis $-14^{\text {th }}$ BMOS - September 01-05, 2011-Brasilia, Brazil 